\title{
Thoughts on the Teaching Reform of Cultivating Innovative Talents in Military Academies
}

\author{
Zhang Wen ${ }^{1, a}$, Zhang Qian ${ }^{1, b^{*}}$ \\ ${ }^{1}$ Air Defense and Missile Defense College, Air Force Engineering University, Xian, Shanxi, China \\ a499571175@qq.com \\ b*zhangqian8913@163.com
}

\begin{abstract}
With the continuous advancement of the military education policy in the new era, military education and training have placed higher demands on high-quality and innovative talents. Starting from cultivating and adapting to the needs of strategic transformation, creating application-oriented talents with innovative capabilities, this paper analyzes the ability requirements of applied innovative talents in military academies in the new era, and systematically sets up a talent training system, integrated curriculum system design, and optimization of main and auxiliary Curriculum support and other aspects discussed the teaching reform plan, and discussed the role of a complete structure and complete function of the practical teaching system on talent training. The research of the thesis provides ideas and references for the training of innovative and applied talents in military academies.
\end{abstract}

Keywords: Talent training, military academies, teaching reform, curriculum system

\section{军队院校创新人才培养的教学改革思考}

\author{
张文 $1, \mathrm{a}$ 张倩 $1, \mathrm{~b}^{*}$
}

1 空军工程大学防空反导学院, 西安, 陕西, 中国

a499571175@qq.com

$b^{*}$ zhangqian8913@163.com

\section{摘要}

随着新时代军事教育方针持续推进, 军事教育训练对高素质、创新型人才提出了更高的要求。从培养适应战略 转型需要, 打造具有创新能力的应用型人才出发, 对新时代军队院校应用型创新人才的能力需求进行了分析, 从系统设置人才培养体系、一体化课程体系设计以及优化主辅课程配套等方面对教学改革方案进行探讨, 论述 了结构完整、功能完备的实践教学体系对人才培养的作用, 论文的研究对军队院校创新应用型人才培养提供了 思路和参考。

关键词: 人才培养; 军队院校; 教学改革; 课程体系

\section{1. 前言}

随着军队新时代军事教育方针和空军战略转型 的持续推进, 军事教育训练对高素质、创新型人才提 出了更高的要求。新时代军队院校教育创新必须适应 时代发展、紧贴部队岗位能力需要, 确立与军事装备 发展相适应的新的教育观和人才观 ${ }^{[1]}$ 。正如杨振宁博 士所说: 西南联大教会了他严谨, 西方大学教会了他 创新。这足以反映不同教育观念对学生培养的作用和
效果不同。军校教育对学生创新精神和创新能力培养 有许多成功的经验, 但目前我们的教学中有不少环节 存在着重理论、轻实践, 重知识传授、轻能力培养的 现象, 这在很大程度上制约了学生创新素质的形成及 创新能力的提高, 不利于军校应用型创新人才的培养 $[2,3]$ 。目前, 面对刚刚跨入战略空军门槛的军种, 防 空反导部队作为未来的战略力量, 在我国领土防空中 扮演着极为重要的角色。军校是军队培养人才的摇篮, 其中, 防空反导学院肩负着防空反导人才培养的重任。 
如何为部队培养适应新军事任务需要、具有较强创新 能力的应用型人才, 是我们每个从事军校教育的人应 该认真思考的问题。在军校的教学实践中, 我们必须 坚持以学员为主体的教育教学观念, 确立培养创新型 军事人才的教育价值观念, 加强和完善创新型军事人 才的培养环节, 构建新时代军校应用型人才的培养方 案和课程体系, 构造功能完备的实践教学体系, 为创 新人才的培养奠定良好的基础。

\section{2. 新时代军校应用型创新人才的能力需求}

高校培养的人才目标定位, 根据创新活动的性质 可以分为研究型、综合型、应用型。其中研究型人才 主要是从事各种理论研究, 及各种科学技术研究、设 计与创造的人才, 他们的创新活动主要侧重于较高层 次与较深的领域 ${ }^{[4]}$ 。应用型人才主要侧重于实践操作。 综合型创新型人才主要是指既能进行理论上的研究, 又能进行实践上创新的复合型人才。军校培养的人才 应该是既能进行理论上的研究, 又能进行实战上技术 保障和兵器操作, 是专业性、针对性和应用性很强的 专门人才。军校培养的应用型本科创新人才应具有较 强的装备工程实践能力和兵器操作能力、扎实的专业 业务素质与全面的综合素质、良好的团队合作精神及 较强的创新意识和创新能力。

\section{1 具有较强的装备工程实践能力和兵器操 作能力。}

较强的军事装备工程实践动手能力和兵器操作 技能, 是军校应用型本科创新人才区别于其他人才的 一个重要能力特征。我们培养的本科毕业生, 应具有 及时发现和熟练解决军事装备问题的能力, 能敏捷地 在作战、管理和部队服务一线发现潜在的问题, 熟练 地运用各种知识和技能解决部队兵器的实际问题。具 有较强的装备工程实践能力和兵器操作能力是部队 的需求, 更是军队院校培养应用型人才的需求, 扎实 的工程实践能力和兵器操作能力是培养创新型人才 的前提, 具备较强的操作能力, 有利于创新能力的生 成。

\section{2 具有扎实的专业业务素质与全面的综合 素质。}

学科专业知识是直接反映部队岗位的能力需求, 是人才应该具有的基本知识体系, 但在防空反导的实 际作战中遇到的问题往往不是单一的问题, 而是综合 的、复杂的一些问题。随着部队新装备的更新发展, 根据防空反导作战任务的要求, 部队岗位的内涵和外 延处于不断深化之中, 对学员全面素质发展与专业业 务素质提出了更高要求。军校应用型本科创新人才的 能力, 不仅仅局限于胜任某个具体型号、单一岗位具 体工作的能力, 还应具有对新装备发展、岗位变动的 良好适应性。随着装备发展的现代化与集成化, 对专 业技能水平的要求更加严格, 只有具有扎实的专业业
务素质, 才能胜任现代化军队岗位。在专业素质提升 的同时, 现代化装备更是对多学科综合能力的考验, 只有具备全面的综合素质，才能经得起时代的挑战。

\section{3 具有良好的团队合作精神}

军校应用型本科创新人才所从事的工作大都是 作战一线部队的装备使用、维护及排除故障等, 面对 对象常常是一线官兵，直接涉及指挥、规划、决策、 应用与协作, 其中的任何一项任务, 都需要团队的创 造与合作, 信任、协作精神是军校应用型本科工程创 新人才的必备品质, 也是当今部队所必须的优秀品质, 教员育人更要把团队合作精神作为培养重点进行。特 别是在对现今高校的零零后新生力量, 他们的个人主 义、独立意识较强, 更要对其加强团队合作精神的培 养教育，做好思政工作，培养出懂合作、顾大局的专 业人才。

\section{4 具有较强的创新意识和创新能力}

创新和创造是各种不同层次的人才都应具备的 核心特征。面对新装备的不断发展、更新换代, 军校 应用型工程人才的教育目标, 更应侧重于 “创新意识” 和 “创新能力” 的培养和提高。因为创新能力、创新 行为是与部队实际问题的创造性解决分不开的, 是与 学员的发展后劲及终身受益分不开的, 只有具有较强 的创新意识和创新能力, 才有可能创造性的解决矛盾 和问题。军队院校要培养适应新型作战的部队人才, 首先要培养具有创新意识、创新精神和创新能力的人 才。

\section{3. 系统构建创新应用型人才的教学改革方案}

根据新时代专业技术和指挥类军官的职能定位, 遵循创新型人才的成长规律, 必须系统优化教学改革 方案。人才培养方案和课程体系是为实现人才培养目 标而设计的具体操作方案, 决定着实现人才培养目标 的可行性。课程设置是培养具有创新能力人才的核心 环节, 只有构建科学合理的课程体系, 才能孕育出高 素质的应用型工程创新人才 ${ }^{[5]}$ 。近年来, 由于新装备 的快速发展、更新换代以及军队改革, 往往使课程模 式定位不准, 多采取以学科知识为中心的课程模式, 严重地出现了 “学问化” 的倾向, 例如理论知识过重, 实践环节比例严重偏少, 淡化了对学员应用能力的培 养; 以学科体系构建课程, 松解了课程与部队要求之 间的联系; 先理论后实践的课程排列顺序, 使理论与 实践出现了严重的时间隔离, 造成了理论与实践不能 有机融合; 随着新装备的发展, 新知识不断出现, 学 校的课程随之而增加, 学员自主学习的时间和空间不 断受到挤压等等, 这些问题阻碍着军校应用型本科创 新人才的培养。因此, 必须积极构建有利于创新精神、 创新能力和实践能力培养的课程体系 ${ }^{[6]}$, 适应新时代 岗位能力需求。 


\section{1 系统设置人才培养体系}

按照人才培养目标和规格要求构建人才培养体 系, 实现知识、能力、素质协调发展。人才培养体系 应该包括理论教学、实践教学和素质拓展三大部分: 在理论课程教学体系, 强调基础较扎实, 专业知识面 宽, 在保证必要的基础理论课程的前提下, 加强专业 基础课程和专业核心课程教学, 培养学员的分析、思 考和创新能力; 在实践课程教学体系, 以一个或多个 新型号装备为背景, 强调工程设计理念和思路、兵器 运用能力培养; 在素质课程教学体系, 通过公共选修 课程拓展知识, 通过课外创新、实践活动和各种竞赛 等, 培养学员的团队意识、创新意识和开拓意识。

\section{2 一体化课程体系设计}

军校期间的学习时间有限, 但任何一门学科、专 业要学的知识都有很多, 学什么、不学什么, 如何取 舍, 应该根据专业培养的目标要求来选择, 切实把学 员大学学习过程作为一个完整的系统进行整体设计 和优化, 其重点不在于一门课程的系统性和完整性, 重要的是强调课程之间的功能区分和内在联系, 从而 避免课程之间不必要的重复, 优化课程结构和内容、 改革教学方式、整合课程设置, 构建融会贯通的一体 化课程体系。

\section{3 优化配套辅助课程设置}

增加选修课程比例, 满足学员个性化需求; 实行 主辅修制度, 满足学员知识拓展和个人发展的要求。 在实现选修课学时比例不低于 $1 / 3$, 实践环节课时不 低于总课时的 $1 / 3$, 课外学时不低于总课时的 $1 / 3$ 方 面进行探索, 为学员个性发展、实践能力培养、自主 学习和独立思考等方面留出时间与空间。创新能力的 培养要发展学员的个性、引导学员的兴趣、拓展学员 的知识, 军队院校应该给予充分的条件支持与人员保 障, 比如设置多样的课程、举办丰富的俱乐部活动、 开放适当的实验平台、提供一定的科研机会, 这些都 能够发展和培养本科学员的创新能力、有利于军队创 新型应用人才的培养。

\section{4 突出动手实践平台构建}

强调理论与实践相结合, 打造有利于学员动手操 作的实践平台，突出实践能力和创新应用能力的培养, 设计与理论教学相对应的实践教学内容, 研发动手实 践平台, 辅助学员完成理论学习的升华和工程应用实 践能力的深化, 真正把学院的理论知识和实践动手能 力稳步提升, 让学员更好、更快的提升自身能力素质。 可以采用虚拟仿真平台与实战实操相结合的方法, 让 学员经过虚拟仿真训练, 熟悉实践目标、实践原理、 实践过程、实践结果等, 将理论知识与仿真实践相结 合, 为实际操练奠定扎实的基础。虚拟仿真平台与实 战实操相结合有利于实际的动手操作, 有利于创新应
用型人才的培养。

\section{4. 科学规划结构完整、功能完备的实践教学 体系}

结构完整、功能完善的实践教学体系是培养军校 应用型、创新型本科技术人才的重要平台。军校现行 的实践教学环节, 在针对培养创新型人才方面, 其系 统性、体系性设计还有很多欠缺。为了提高应用型创 新人才培养的素质, 实践教学环节是至关重要的。军 校教学应本着 “能实不需、虚实结合” 的原则构建成 结构完整、功能完备的实践教学体系。以基础课与实 验课相结合, 以实验中心和专业实验室为平台, 让学 员掌握基本实验的技能和方法, 灵活应用科学知识促 进科学思维和创新思维训练; 以实训中心和工程中心 等为平台，提高学员实践技能和工程分析能力; 以虚 拟仿真平台搭建实验系统为平台, 加深对课程知识的 认知和了解, 掌握相关课程知识的应用方法和设计理 念、设计技巧; 以模拟训练器和部队实习基地为平台, 使学员掌握兵器原理与战术技术应用的关系, 强化军 人素养和责任感; 以综合性的毕业设计为平台, 培养 学员综合运用专业理论、专业知识, 分析、解决装备 问题隐患的能力; 以课外科技创新活动为平台, 学员 通过参加学科竞赛、教员科技立项、科研课题等活动, 增强创新意识和创新能力; 以假期大学生社会实践活 动为平台, 为学员提供了解国情、社会的途径, 使学 员掌握调查研究方法, 提高适应社会的能力。构建军 队院校实践教学体系应把握如下几个方面。

\section{1 建设 “精教勤研” 的实践教学队伍}

教学能力是教员的立身之本, 研究能力是教员提 升自我的途径。建设院级研发中心, 为教员提供研究 基地, 鼓励教员积极申报科研课题, 提供科研经费支 持; 鼓励并组织教员积极参与部队实践锻炼; 教员要 主动研究教学中存在的问题, 提升教学能力, 与时俱 进, 真正了解当今时代部队需要什么样的人才、怎么 样培养人才, 培养什么样的人才。军校教员要教学与 科研并进发展, 用教学促进科研, 用科研反哺教学, 把科研中前沿的知识带进课堂里面去, 让学员实时了 解科技发展的最近领域与动态, 了解现代作战的新技 术、新方向。

\section{2 建设 “行之有效” 的实践教学资源}

充分发挥教员科研课题的优势, 从教员科研课题 或技术开发项目中选择内容丰富的题材, 鼓励学员积 极参与。题材要强调综合, 突出创新和实践, 形成富 有特色的实践教学内容, 做到 “真题真做” 的训练效 果, 通过建设资源, 为学员提供实践平台和基础。鼓 励学员参与各种学术交流活动或学科竞赛, 为学员提 供信息渠道、经费资助、辅导帮带等保障措施, 让学 员不局限于学校所学, 能够走出去增长见识、提升能 力, 培养其创新精神与创新能力。 


\section{3 建设 “功能完备” 的实践教学平台}

建设强大的实践教学基地, 是工程院校的重要办 学基础, 更是培养应用型工程技术和作战人员的充分 而必要条件。在校内实验中心建设中, 加强基础教学 实验室建设与改造, 为开展单项能力、技术、技能训 练奠定基础; 依托校内新装备教学和仿真模拟器教学 基地, 开展兵器操作实践教学, 使实践教学设备反映 部队装备发展水平, 使实践教学环境接近部队实战环 境; 在新装备作战部队实习基地建设中, 发挥学校人 才优势, 与部队互帮互学, 达到 “双赢共赢” 的效果。 除了院校建设自己的实践平台、也可借助于部队或基 地的综合实践平台, 增加学员的实践机会, 培养出毕 业就能上岗、上岗就能胜任的人才。

\section{4 建设 “规范严格” 的教学管理制度}

要以军校人才培养计划为依据, 不断积累实践教 学经验。针对实验、实训、部队定岗实习等实践教学 环节, 不断修订和完善实践教学质量监控体系和学员 实践考核评价标准等, 形成形势正规、管理规范、考 核严格的实践教学运行机制。教学应着重培养学员的 主动思考能力, 教员在学习过程中起到答疑解惑作用 的同时, 更要激发学员主动思考问题的能力和方式。 “授人以鱼不如授人以渔” 真正从方式方法上教导学 院如何思考、如何学习。好的教学管理制度能够激发 学员的创新意识、有利于培养其创新能力, 军队院校 应制定适宜于学员全面发展的管理制度, 跟上时代的 步伐, 让管理制度与时俱进。

\section{5. 小结}

落实新时代军事教育方针, 培养军校应用型、创 新型人才, 涉及教学的诸多环节。只有确立与军事装 备发展相适应的新的教育观和人才观, 才能正确理解 应用型本科创新人才主要特征和未来信息化作战对 人才能力素质的需求特点, 才能实现人才培养目标。 通过设计合理的培养方案和课程体系, 建设行之有效 的实践教学体系和教育平台, 才能确保军校培养出高 素质的应用型、创新型人才, 才能为我军在信息化战 争中占据技术优势和人才优势提供强有力的保障。

\section{REFERENCES}

[1] Li Shuangxun, Jiang Yanwen, Wang Zhan, et al. A preliminary study on the construction of training conditions for military talents in electronic information in the new era [J]. Industry and Information Education. 2021, (2). 89-94.

[2] Wang Shibin, Gu Yuzhu, Qie Haixia. Analysis of the three-dimensional structure of the innovation and development of new engineering education[J]. China Higher Education Research, 2019, 10: 68-73.

[3] Li Peigen. Several important perspectives of future engineering education [J]. Higher Engineering Education Research, 2019, 2:40-43.

[4] Liu Yajie, Li Zhongmeng, Shi Lianhui, etc. Research on talent training model for professional technical positions in aircraft carriers [J]. Journal of Naval University of Engineering, 2017, 14 (4): 70-74.

[5] Wang Dan, Lu Yang, Sun Mingmei. Research on the Construction of Information Literacy Education System in Military Academies [J]. Intelligence Exploration, 2019, 9:28-32.

[6] Chen Xiao, Han Fei, Xie Yongfen, etc. Analysis of the Trinity New Military Talent Training System[J]. Modern Vocational Education, 2019,19:1-3. 